\title{
Dissipation pattern and risk assessment of the synthetic pyrethroid Lambda- cyhalothrin applied on tomatoes under dryland conditions, a case study
}

\author{
Farag Malhat ${ }^{1^{*}}$, Naglaa M. Loutfy ${ }^{2}$ and Mohamed Tawfic Ahmed ${ }^{2^{*}}$
}

\begin{abstract}
Background: The present study was carried out to develop and validate an analytical method for the detection and quantification of lambda-cyhalothrin, a synthetic pyrethroid insecticide, in tomato using gas chromatographyelectron capture detector (GC-ECD). The study has meant to ascertain lambda-cyhalothrin dissipation behavior under dry land conditions.

Results: The analytical method was validated using blank tomato spiked at $0.01,0.1$ and $0.5 \mathrm{mg} / \mathrm{kg}$, with satisfactory recoveries ranging between 92.3 to $95.1 \%$ and relative standard deviations (RSDs) $<13.4 \%$. Good linearity was achieved, with a determination coefficient $\left(R^{2}\right)$ of 0.999 for the $0.005-2.0 \mathrm{mg} / \mathrm{L}$ concentration range. The limits of detection and quantification were 0.005 and $0.01 \mathrm{mg} / \mathrm{kg}$, respectively. Dissipation pattern of lambda-cyhalothrin applied on open field grown tomato was also assessed using the same method. Lambda-cyhalothrin residues declined very quickly following first-order rate kinetics with half-life of 3.12 days. At harvest time, 14 days after final application, the remaining residues of lambda-cyhalothrin were below CODEX maximum residue limit (MRL) of $0.05 \mathrm{mg} / \mathrm{kg}$.

Conclusions: Exposure of lambda-cyhalothrin has been assessed and compared to acceptable daily intake (ADI). The assessment of consumers' exposure was based on the international estimated daily intake (IEDI) compared to acceptable daily intake (ADI). The long-term risk assessment was performed by calculating the hazard quotient (HQ). Since the $\mathrm{HQ}_{\text {Chronic }}$ of lambda-cyhalothrin never exceeded $1.2 \%$, the tomato fruits could be considered safe for human consumption 14 days after application of lambda-cyhalothrin at the recommended dose.
\end{abstract}

Keywords: Lambda-cyhalothrin, Residue, Risk assessment, Degradation pattern

\section{Background}

Pesticides are biologically active compounds used worldwide for the protection of food, fiber, and human health (Malhat et al., 2015). After application, pesticides tend to degrade, with their residues remaining not only in the plants but also in various environmental matrices, like water, soil or sediments. Pesticides have been reported to cause toxic effects on humans, ranging from short-term effects such as headaches and nausea to chronic effects

\footnotetext{
* Correspondence: fmmalhat@gmail.com; motawfic@tedata.net.eg

'Pesticide Residues and Environmental Pollution Department, Central

Agricultural Pesticide Laboratory, Agricultural Research Center, Dokki, Giza 12618, Egypt

${ }^{2}$ Plant Protection Department, Faculty of Agriculture, Suez Canal University, Ismailia, Egypt
}

\section{Springer Open}

(C) 2016 The Author(s). Open Access This article is distributed under the terms of the Creative Commons Attribution 4.0 International License (http://creativecommons.org/licenses/by/4.0/), which permits unrestricted use, distribution, and reproduction in any medium, provided you give appropriate credit to the original author(s) and the source, provide a link to the Creative Commons license, and indicate if changes were made. like cancer, reproductive damage and endocrine disrup2014a). Humans main exposure route is via food that contribute five times more than other routes, such as air and drinking water (Claeys et al., 2011; Malhat et al. 2014b).

Pesticides - contaminated food is associated with severe effects on the human health. It is therefore rather important to work out strategies to enhance safe application of pesticides use. Maximum residue levels (MRLs) are useful parameters that promote food safety by restricting the concentration of a pesticide residue permitted on a commodity (Chen et al., 2011; Claeys et al., 2011; Malhat \& Hassan, 2011). 
Pyrethroids are axonic poisons that affect the nerve fiber by binding to a protein that regulates the voltage-gated sodium channel. Normally, this gate opens to cause stimulation of the nerve and closes to terminate the nerve signal. There are two groups of pyrethroids with distinctive poisoning symptoms, denoted as Type I and Type II. Chemically, Type II pyrethroids are distinguished from Type I pyrethroids by the presence of a cyano group in their structure. In comparison to Type I pyrethroids (e.g., permethrin), which exert their neurotoxicity primarily through interference with sodium channel function in the central nervous system, Type II pyrethroids (e.g., lambda-cyhalothrin, (Fig. 1) can also affect chloride and calcium channels that are important for proper nerve function (Burr and Ray 2004).

Lambda-cyhalothrin $\quad[(\mathrm{R}, \mathrm{S})$ - $\alpha$-cyano-3-phenoxybenzyl (1S)-cis-3-[(Z)-2-chloro-3,3,3-trifluoropropenyl]-2,2-dim ethylcyclopropanecarboxylate], has been widely used to control chewing and sucking insect pests in field crops, beside its wide use in public health (Davey et al., 1992; Roberts et al., 1993; Dikshit et al., 2000; Mathirajan et al., 2000). Information about the dissipation rate of a pesticide after application is a valuable tool for assessing the behavior of residues and estimating the preharvest interval (PHI) (Malhat et al. 2014a). Governments and international organizations are regulating the use of pesticides and are setting the acceptable MRLs in foods. Good knowledge of the pesticide fate in foodstuffs is an important regulatory need to assess human exposure and possible environmental risks. Reliable estimate of long-term dietary intake of pesticide residues are needed to ascertain chronic risk. The consumer is considered to be adequately protected when estimated dietary intake of pesticide residues does not exceed the ADI or the acute reference dose (ARfD) (WHO 1997).

Lambda-cyhalothrin is mainly detected and analyzed via gas chromatography (Bouldin et al., 2006; Hem et al., 2010; Seenivasan and Muraleedharan, 2009). A microextraction method followed by GC analysis was reported for lambda- cyhalothrin in vegetables (Vazquez, et al., 2008). However, for field trial and dissipation study, microextraction data is sometimes unable to reflect the real field sample due to the sample amount. In turn, an effective simultaneous method is needed for lambda-cyhalothrin to enable handling sufficient representative sample to generate data for regulation.

In Egypt, along with most dry countries information about the dissipation of lambda-cyhalothrin insecticides is very limited. Therefore the aim of the present investigation was to develop a simultaneous method for the detection of lambda-cyhalothrin in tomato grown under open field condition using GC- $\mu \mathrm{ECD}$. The data generated from residue determination were used to estimate the dissipation pattern of lambda-cyhalothrin in tomato.

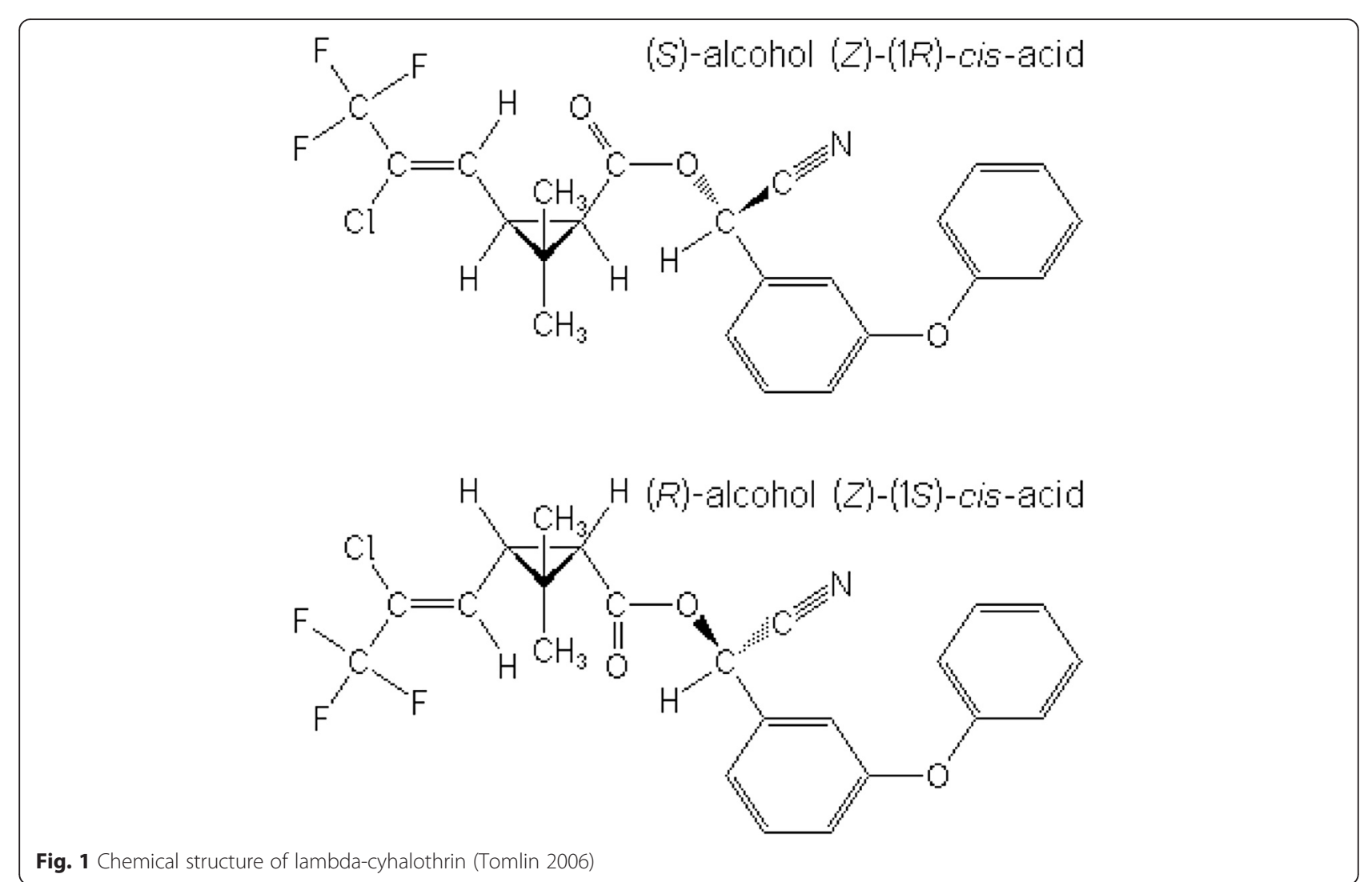


Furthermore, the safety constants viz half-life and preharvest interval (PHI) of lambda-cyhalothrin were assessed to the help growers promoting Good Agricultural Practices (GAP).

\section{Methods}

Chemicals

Certified reference standard of lambda-cyhalothrin ( $>99 \%$ purity) were purchased from Dr. Ehrenstorfer $\mathrm{GmbH}$ (Augsburg, Germany). All solvent used were residue analysis and HPLC grade and were obtained from Scharlau (Barcelona, Spain). Primary secondary amine (PSA, $40 \mu \mathrm{m}$, Bondesil), and graphitized carbon black (GCB), were procured from United Chemical Technology (Bristol, PA, USA). Anhydrous sodium sulfate (analytical reagent grade) was purchased from Merck (Germany) and activated by heating at $130{ }^{\circ} \mathrm{C}$ for $12 \mathrm{~h}$ and kept in desiccators. Sodium chloride of analytical grade was obtained from El Naser Pharmaceutical Chemicals Company (Cairo, Egypt).

\section{Standard solution}

Standard stock solution of $100 \mathrm{mg} / \mathrm{L}$ lambda-cyhalothrin was prepared in ethyl acetate. These were stored in dark vials at $-20{ }^{\circ} \mathrm{C}$. A working standard solution of $1 \mathrm{mg} / \mathrm{L}$ was prepared by appropriate dilution of the stock solution, from which the calibration standards $(0.005-2.0 \mathrm{mg} / \mathrm{L})$ were prepared by serial dilution with ethyl acetate. A matrix-matched standard calibration was obtained by mixing working standard solutions with blank tomato extracts. All standard solutions were stored at $-20{ }^{\circ} \mathrm{C}$ in dark amber bottles until further analysis.

\section{Field experiment design}

The field trails including the dissipation study and final residue study were conducted in a randomized block design in open field. Each experiment was conducted in four separate plots measuring $20 \mathrm{~m}^{2}$ each where three plots were used for insecticide treatment and the other plot was used as control (blank sample). None of the plots had been treated with lambda-cyhalothrin in the past. There was no rainfall at any time during the experimental period.

\section{Residue dynamic experiments}

To investigate the dissipation of lambda-cyhalothrin, tomato had one single spray with lambda-cyhalothrin formulation (Lambda $5 \%$ EC), using the recommended rate, i.e. $20 \mathrm{~g}$ a.i./ha. Tomato fruits were collected at random at 0 ( $2 \mathrm{~h}$ after spraying), 1, 3, 7, 10 and 14 days after the treatment. Immediately after picking, the samples were put into polyethylene bags and transported to the laboratory, where they were chopped and thoroughly mixed. The sample was kept deep-frozen $\left(-20^{\circ} \mathrm{C}\right)$ until analysis. Control samples were obtained from the control plot.

\section{Final residue experiments}

To investigate the final residues of lambda-cyhalothrin in tomato, the commercial formulation of lambda-cyhalothrin was manually sprayed at recommended dosage of $20 \mathrm{~g}$ a.i./ha two and three times at an interval of 14 days. Representative tomato samples were collected at 7 and 14 days after last treatment. Collected tomato samples were chopped immediately after harvesting and thoroughly mixed, packed in polyethylene bags, labeled, and stored at $-20{ }^{\circ} \mathrm{C}$ until analysis.

\section{Sample preparation}

A $10 \mathrm{~g}$ of the homogenized sample were placed into $50-\mathrm{mL}$ Teflon centrifuge tube to which $10 \mathrm{~mL}$ of ethyl acetate was added and vigorously shaken for 1 min using a vortex mixer at maximum speed. Next $10 \mathrm{~g}$ sodium sulfate anhydrous was added, and the sample was vortexed for $30 \mathrm{~s}$. The extracts were centrifuged for $5 \mathrm{~min}$ at $3800 \mathrm{rpm}$ and $4{ }^{\circ} \mathrm{C}$. An aliquot of $4 \mathrm{~mL}$ was transferred from the supernatant to new clean $15-\mathrm{mL}$ centrifuge tube and cleaned up by dispersive solid-phase extraction with $100 \mathrm{mg}$ PSA, $20 \mathrm{mg}$ GCB. The sample was again vortexed for $1 \mathrm{~min}$ and then centrifugation was carried out as mentioned above. Then, an aliquot of the supernatant was decanted, filtered through a $0.22-\mu \mathrm{m}$ PTFE filter (Millipore, Billerica, MA) and transferred into a glass vial for GC analysis.

\section{Instrument analysis}

The GC- ECD system consisted of a Hewlett Packard 6890 network GC system equipped with $\mathrm{Ni}^{63}$ micro electron capture detector $(\mu-E C D)$. The analyte was separated on a HP-5MS capillary column (30 m length $\mathrm{x} 0.32 \mathrm{~mm}$ (i.d) $\mathrm{x} 0.25 \mu \mathrm{m}$ film thickness, Agilent Technologies, Santa Clara, CA, USA). The injector and detector temperatures were maintained at 280 and $300{ }^{\circ} \mathrm{C}$, respectively. The column oven temperature was held at $160{ }^{\circ} \mathrm{C}$ for $2 \mathrm{~min}$, which was raised to $260{ }^{\circ} \mathrm{C}$ at $3{ }^{\circ} \mathrm{C} / \mathrm{min}$ and held for $5 \mathrm{~min}$. Nitrogen was used as carrier gas flow at $4 \mathrm{ml} / \mathrm{min}$. $1 \mu \mathrm{L}$ injection volume was injected at splitless mode.

\section{Method validation}

The analytical method of lambda-cyhalothrin in tomato was validated for tomato for parameters such as linearity, precision, specificity and assay accuracy by following guidance document on residue analytical methods (SANCO/ 12571/2013).

\section{Linearity}

The linearity of the method was calculated from the results directly proportional to the concentration of lambdacyhalothrin in solvent. Linearity was assessed by the correlation coefficient $\left(R^{2}\right)$ resulted from the five-point calibration curve. 


\section{Accuracy}

Accuracy was obtained from recovery studies carried out by spiking sample $(n=3)$ with standards at levels of $1 \mathrm{x}$ LOQ $(0.01 \mathrm{mg} / \mathrm{kg}), 10 \times$ LOQ $(0.1 \mathrm{mg} / \mathrm{kg}), 50 \times$ LOQ $(0.5 \mathrm{mg} / \mathrm{kg})$. Recovery was calculated using the following equation:

$$
\% \text { Recovery }=100 \frac{\text { Measured Concentration }}{\text { Spiked }(\text { added }) \text { concentration }}
$$

\section{Precision}

The precision of the method was determined by assessing repeatability and reproducibility, expressed as RSD $\%$ values. The repeatability relative standard deviation $\left(R S D_{r}\right)$ was measured by comparing the standard deviation values of the recoveries from spiked samples analyzed on the same day. The reproducibility relative standard deviation $\left(R S D_{R}\right)$ values were determined by the analyses of spiked samples on 3 different days.

$$
\% R S D=100 \frac{S D}{M}
$$

Where $S D$ is the standard deviation of the replicate, and $M$ is the mean value of the recovery

\section{Matrix effect}

The matrix effect of the present method was investigated by comparing standard dissolved in solvent with matrixmatched standard for 5 replicates at 0.01 , and $0.5 \mathrm{mg} / \mathrm{kg}$. Matrix effect (\% ME) was calculated using the following equation:

$$
\% M E=100 \frac{M_{\text {matrix }}-M_{\text {solvent }}}{M_{\text {matrix }}}
$$

Where $\% M E$ is the matrix effect, and $M_{\text {matrix }}$ and $M_{\text {solvent }}$ are the slopes of calibration curves in the matrix and in pure solvent, respectively.

\section{Limits of detection (LOD) and quantification (LOQ)}

The LOD was calculated as the quantity of lambdacyhalothrin that generated a response 3 times greater than the noise level according to ICH method (Ermer et al. 2005). The LOQ was defined as the lowest concentration of lambda-cyhalothrin in tomato that has been validated with acceptable trueness (70-120 \%) and precision $(R S D r \leq 20 \%)$ by applying the complete analytical method, defined as a signal-to-noise ratio $(\mathrm{S} / \mathrm{N})$ of 10:1. According to the document SANCO/12495/2013 (SANCO, 2013) the limit of quantification should be $\leq$ MRL. The maximum residue level (MRL) for lambda-cyhalothrin is $0.05 \mathrm{mg} / \mathrm{kg}$ for tomato (Codex Alimentarius Commission, 2011).

\section{Kinetic curve fitting}

The dissipation kinetics of lambda-cyhalothrin in tomatoes were determined by plotting the residue concentration against time and the maximum squares of correlation coefficient found were used to determine the equations of best fit curves. For all the samples studied, exponential relationships were found to apply, corresponding to the first order rate equation. Confirmation of the first order kinetics was further made graphically from the following equation:

$$
C_{t}=C_{0} e^{-k t}
$$

Where $C_{t}$ represents the concentration of lambdacyhalothrin residue at the time of $t$, while $C_{0}$ represents the initial deposits after application and $k$ is the degradation rate constant in days ${ }^{-1}$. The half-life $\left(t_{1 / 2}\right)$ was calculated from the $\mathrm{k}$ value for each experiment, being:

$$
t_{1 / 2}=\frac{\ln 2}{k}
$$

\section{Results and discussion Optimization of sample preparation}

Extraction efficiency and stability of lambda-cyhalothrin was optimized through two different organic solvent: acetonitrile and ethyl acetate. Formation of lambda-cyhalothrin isomers was recorded in the chromatogram of tomato extracted with acetonitrile. On the other hand, no isomers appeared in the chromatogram of ethyl acetate extract. Therefore, ethyl acetate was selected as the most suitable solvent for extraction of lambda-cyhalothrin from tomato in this study. In the present study both PSA and GCB purification capabilities were also studied. The tomato extract was acidic due to the naturally high content of organic acids, which have been removed to a great extent by the PSA sorbent. Lambda-cyhalothrin was not retained by $\mathrm{GCB}$, while many interfering matrix compounds were removed. This indicated that PSA and GCB provide sufficient cleanup for the crude extract of tomato.

\section{Method validation}

Recoveries of lambda-cyhalothrin at different fortification levels validated the procedures adopted for extraction and analysis of lambda-cyhalothrin residues in tomato samples. The recovery achieved was $92.6 \%$ at $0.01 \mathrm{mg} / \mathrm{kg}$ level of fortification, $95.1 \%$ at $0.1 \mathrm{mg} / \mathrm{kg}$ level and $92.3 \%$ at $0.5 \mathrm{mg} / \mathrm{kg}$ level of fortification for tomato which was a clear validation of the procedure adopted for extraction and analysis of lambda-cyhalothrin residues in tomato samples. The obtained value confirmed that the ethyl acetate sample preparation coupled with the GC-ECD analysis is quite suitable for the determination of the residues of lambda-cyhalothrin in tomato. Good linearity was achieved for lambda-cyhalothrin over five concentration 
levels ranging from 0.005 to $2 \mathrm{mg} / \mathrm{L}$, with excellent correlation coefficient of 0.9999 . The precision of the method was determined by analyzing the relative standard deviation $(R S D<20 \%)$ in the observed area. It is suggested that lambda-cyhalothrin can be detected with good precision provided the extraction procedure adopted good recoveries. The specificity and selectivity of this method was achieved by obtaining an identical retention time for injected standard as well as spiked samples. The interferences with the analyte were examined by comparing the chromatograms of standard, blank and fortified samples. Results showed that, no interfering endogenous peak appeared, and the matrix dose not significantly suppress or enhance the response of the instrument. The limit of detection and quantification for lambda-cyhalothrin were 0.005 and $0.01 \mathrm{mg} / \mathrm{kg}$, respectively. SANCO/12571/2013 (SANCO, 2013), suggested that the LOQ values are acceptable where LOQ $\leq$ MRL ( $0.05 \mathrm{mg} / \mathrm{kg}$ for tomato), indicating that the method was sensitive and able to detect and quantify the analyte at very low levels. The obtained results are within acceptable validation criteria for pesticide residue analysis (SANCO/12571/2013) and indicated that the developed method was accurate and reproducible.

\section{Dissipation of lambda-cyhalothrin in tomato}

For better understanding of the possible hazardous impacts of pesticides residues, dissipation studies are necessary to examine the appropriateness of pesticides application strategies ( $\mathrm{Lu}$ et al., 2014). The degradation kinetics of lambda- cyhalothrin in tomatoes was determined by plotting residue concentrations against time, and the maximum squares of correlation coefficients obtained were used to determine the equation of best-fit curves. For all samples, exponential relations $\left(R^{2}>0.889\right)$ were found to apply, corresponding to first-order rate equation. The half-life $\left(t_{1 / 2}\right)$, dissipation regressive equation, and correlation coefficient $\left(r^{2}\right)$ are summarized in Table 1.

The dissipation curves of lambda-cyhalothrin in tomato under field conditions are shown in Fig. 2. The behavior of lambda-cyhalothrin residue was investigated on tomato to evaluate the diluting effect of the residue caused by plant growth during the experiment. The initial concentration of lambda-cyhalothrin in tomato was $0.718 \mathrm{mg} / \mathrm{kg}$ with half-life of 3.12 days. Residue at one day was $0.445 \mathrm{mg} / \mathrm{kg}$, corresponding to $67.3 \%$ from the initial dose. As shown in Fig. 2, there was a sharp decrease in the amount of lambda-cyhalothrin residues three days

Table 1 Regression equation, correlation coefficient, and half-life of lambda-cyhalothrin in tomatoes

\begin{tabular}{lll}
\hline Regression equation & Correlation coefficient $\left(R^{2}\right)$ & Half-life (days) \\
\hline$C_{t}=0.5908 e^{-0.222 t}$ & 0.9882 & 3.121 \\
\hline
\end{tabular}

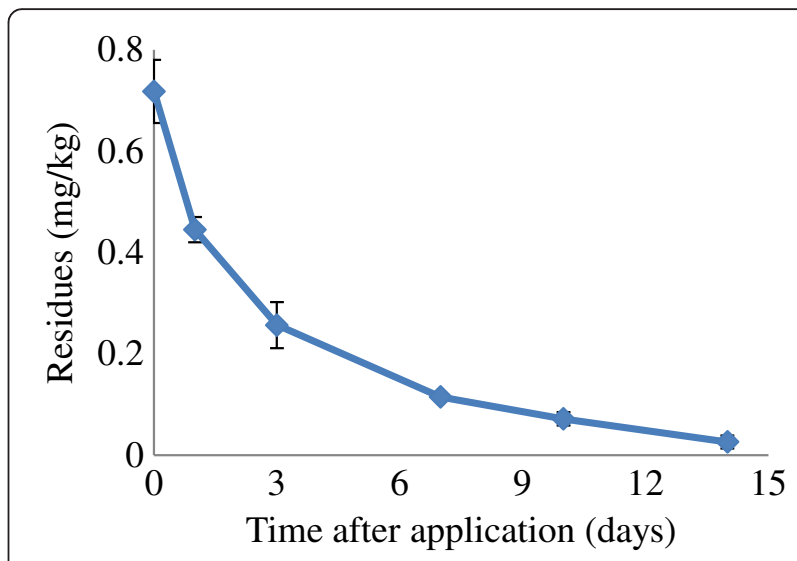

Fig. 2 Decline pattern $(n=3)$ of lambda-cyhalothrin in tomato. Data present residue amount, and error bars present standard deviation

after application. In the present study, results indicated that residues have declined by $98.71 \%$ after 14 days. The decline of residues was significantly ascribed to the growth diluting effect and the degradation of the pesticide itself. There are many factors that influence the fate of pesticide in plants, including the characteristics of the pesticide (including its over-all stability either as parent compound or metabolites, its volatility, solubility, formulation), and the method and site of application (Aydinalp \& Porca, 2004; Voutsas et al., 2005; Brady et al., 2006; Isenring \& Madeley, 2006; Cabras et al., 1989; Malhat et al., 2013). Additionally, the growth dilution factor might have played a significant role (Cabras et al., 1990; Malhat et al. 2014a). Other plant - dependant factors would include the plant species involved, the nature of the harvested crop, the structure of the cuticle, the stage and the general condition of the plant, in addition to the relation between the treated surface and its weight and living state of the plant surface (Khay et al. 2008; Cabras et al. 1990).

The dissipation half-life of lambda-cyhalothrin in tomato was 3.12 days. In this context, Jayakrishnan et al. (2005) found that lambda-cyhalothrin residues followed first order kinetics with half-life of 3.6-4.5 days and 3.7-3.9 days from first and second spray, respectively, whereas the reported concentration declined with time and reached non-detectable after 7-10 days of treatment in tomato from first year trial.

\section{Final residue levels and safety evaluation}

The final residue of lambda-cyhalothrin at harvest time is shown in Table 2. The tomato was sampled two times during the harvest period to analyze lambda- cyhalothrin residues. When lambda-cyhalothrin was sprayed at the recommended dosage 2 and 3 times, the final residue in tomato was $0.012-0.461 \mathrm{mg} / \mathrm{kg}$. According to the terminal residue results, the residue behaviour of lambda-cyhalothrin 
Table 2 Terminal residue of lambda-cyhalothrin in tomatoes

\begin{tabular}{llll}
\hline Dosage & $\begin{array}{l}\text { Number of times } \\
\text { sprayed }\end{array}$ & $\begin{array}{l}\text { Days after } \\
\text { spraying }\end{array}$ & $\begin{array}{l}\text { Residues in tomatoes } \\
(\mathrm{mg} / \mathrm{kg})\end{array}$ \\
\hline (20 g a.i/ha) & 2 & 7 & 0.103 \\
& 3 & 14 & 0.021 \\
& & 7 & 0.135 \\
& 14 & 0.035 \\
\hline
\end{tabular}

in tomato followed a trend in which shorter harvest intervals led to more residual lambda- cyhalothrin. Food safety is an area of growing worldwide concern. The presence of harmful pesticide residues in food has caused a great concern among the consumers. The Codex MRL for lambda-cyhalothrin in tomato was $0.05 \mathrm{mg} / \mathrm{kg}$. In the present study, and based on the residue level at harvest time, the maximum final residue in tomato at intervals of 14 days post treatment was below the MRLs of $0.05 \mathrm{mg} / \mathrm{kg}$. This result suggested that it is safe to harvest 14 days when applying the recommended dose of lambda-cyhalothrin. The residue content and preharvest interval are closely related to spraying dose and spraying times (Zhang et al., 2006; Zhao, 2000).

\section{Long term dietary intake and chronic risk assessment}

Long-term consumer exposure to lambda-cyhalothrin residues is estimated according to the WHO/FAO method (WHO 1997). Residues data are combined with cultural dietary information (GEMS Cluster Diets) to estimate residue intake by consumers. The consumer is considered to be adequately protected providing the calculated intake of residues does not exceed the acceptable daily intake or the acute reference dose. Based on supervised trial value, the supervised trial median residue (STMR) in tomatoes was $0.069 \mathrm{mg} / \mathrm{kg}$ (Table 2).

The IEDI is a prediction of the long-term daily intake of a pesticides residues on the basis of the assumptions of average daily food consumption per person and median residues from supervised trials. The IEDI calculation reported here considers potential residues from use of lambda-cyhalothrin on tomato. The IEDI is calculated using food consumption data from the GEMS/Food Cluster Diet (cluster diet G06) (GEMS/FOOD 2014), together with lambda-cyhalothrin residues represented by STMR value calculated. The IEDI is compared to the relevant toxicological end-point, the acceptable daily intake (ADI). The ADI of lambda-cyhalothrin was established as $0.02 \mathrm{mg} / \mathrm{kg}$ bw based on its non observed adverse effect level (NOAEL) of $2 \mathrm{mg} / \mathrm{kg}$ bw per day and a 100 -fold coefficient of safety factor. The body weights assumed in the IEDI calculation are $60 \mathrm{~kg}$ (cluster diet G06).

The IEDI calculation gives an unrealistic worst-case estimate of intake because it assumes that $100 \%$ of crops with established and proposed uses will contain residues at the
STMR. No account is taken of the potential reduction in residues during transport and storage. In practice, the actual intake is likely to be much lower than the calculated values. The IEDI was defined according to the following formula:

$$
I E D I=\frac{S T M R * 0.214}{60}
$$

Where $0.214 \mathrm{~kg} /$ Egyptian adult was the daily dietary intake of tomatoes according to GEMS/Food regional diet, (GEMS/FOOD 2014). IEDI of lambda-cyhalothrin in tomato was $2.46 \times 10^{-4} \mathrm{mg} / \mathrm{kg}$ bw.

The long-term risk assessment was performed by calculating the hazard quotient (HQ) by dividing the international estimated daily intake by the relevant acceptable daily intake:

$$
H Q_{\text {chronic }}=\frac{I E D I}{A D I}
$$

The calculated percent IEDI and ADI ratios was $\mathrm{HQ}_{\text {Chronic }}=1.2 \%$ for Egyptian adults.

When $\mathrm{HQ}_{\text {Chronic }} \% \quad 100 \%$, then the chronic risk of lambda-cyhalothrin is unacceptable; the higher the $\mathrm{HQ}_{\text {Chronic }} \%$, the greater the chronic risk. The result indicates that, there is no unacceptable chronic risk to human health from the consumption of tomato treated with lambda-cyhalothrin according to the use considered.

\section{Conclusion}

Residues of lambda-cyhalothrin were successfully extracted from tomato samples using the QuEChERS method with slightly modification. The developed method demonstrated acceptable accuracy and precision and was successfully applied to the dissipation kinetics of lambda-cyhalothrin in tomato from the field. This study is the first record about the dissipation behaviour of lambda-cyhalothrin in tomato under Egyptian field condition, usually known as dry conditions. The present results suggested that it is safe to harvest lambda-cyhalothrin treated tomatoes 14 days after treatment. This finding would help the government to provide guidance on the proper and safe use, and establishing local maximum residue levels (MRL) for lambdacyhalothrin. The present study has portrayed the dietary intake of lambda- cyhalothrin, based on tomato consumption. Nevertheless, the dietary intake study is not necessarily inclusive of vulnerable consumers specially children. Moreover, the study has not included the effect of tomato washing as the standard procedure before consumption of tomato and how such practice would affect residue level. With such shortcoming in mind, the present pilot study is a prelude to a more comprehensive study that would delineate on the full spectrum of risk assessment. 


\section{Acknowledgements}

The authors would like to acknowledge the support provided by the Suez Canal University, Central Pesticides Laboratory-Agriculture Research Centre, for providing the facilities, chemicals, instrumentation used in the present study. The authors would like to thank the anonymous reviewers for their valuable suggestions.

\section{Authors' contributions}

FM has designed the experimental setting, performed the analytical work, and helped in the writing up. NL contributed in results analysis, determining risk assessment and dissipation rate. TA has helped in data interpretation, and writing up. All authors read and approved the final manuscript.

\section{Competing interests}

The authors declare that they have no competing interests.

Received: 17 February 2016 Accepted: 8 July 2016

Published online: 29 July 2016

\section{References}

Aydinalp C, Porca MM. The effects of pesticides in water resources. J Cent Eur Agric. 2004;5(1):5-12

Berrada H, Fernandez M, Ruiz MJ, Molto JC, Font G. Surveillance of pesticide residues in fruits from Valencia during twenty months (2004/05). Food Control. 2010;21(1):36-44.

Bouldin JL, Farris JL, Moore MT, Smith Jr S, Cooper CM. Hydroponic uptake of atrazine and lambda-cyhalothrin in Juncus effusus and Ludwigia peploides. Chemosphere. 2006;65:1049-57.

Brady JA, Wallender WW, Werner I, Fard BM, Zalom FG, Oliver MN, Wilson BW, Mata MM, Henderson JD, Deanovic LA, Upadhaya S. Pesticide runoff from orchard floors in Davis, California, USA: a comparative analysis of diazinon and esfenvalerate. Agric Ecosyst Environ. 2006;115(1-4):56-68.

Burr SA, Ray DE. Structure-activity and interaction effects of 14 different pyrethroids on voltage-gated chloride ion channels. Toxicol Sci. 2004;77:341-6.

Cabras P, Meloni M, Cabitza F, Cubeddu M. Pesticide residues in lettuce. 2. Influence of formulation. J Agric Food Chem. 1989:37:1405-7.

Cabras P, Spanedda L, Cabitza F, Cubeddu M, Martini M, Brandolini G. Pirimicarb and its metabolites residues in lettuce. Influence of cultural environment. J Agric Food Chem. 1990;38:879-82.

Chen C, Qian Y, Chen Q, Tao C, Li C, Li Y. Evaluation of pesticide residues in fruits and vegetables from Xiamen, China. Food Control. 2011;22:1114-20.

Claeys WL, Schmit JF, Bragard C, Maghuin-Rogister G, Pussemier L, Schiffers B. Exposure of several Belgian consumer groups to pesticide residues through fresh fruits and vegetable consumption. Food Control. 2011;22(3-4):508-16.

Codex Alimentarius Commission. "Codex Maximum Residue Limits for Pesticides." http://www.who.int/entity/foodsafety/areas_work/chemical-risks/ IEDIcalculation0217clusterfinal.xlsm. 2011.

Davey RV, Ahrens EH, Goerge JE. Efficacy of cyhalothrin and lambda- cyhalothrin against Boophilus microplus (Acarina: Ixodidae). J Econ Ent. 1992:85:2286-90.

Dikshit AK, Lal OP, Srivastava YN. Persistence of pyrethroids and nicotinyl insecticides on okra fruits. Pestic Res J. 2000;12:227-31.

Ermer J, Miller JH, McB. Method Validation in Pharmaceutical Analysis. KGaA, Weinheim: Wiley-Vch Verlag GmbH and Co. 2005

GEMS/FOOD. GEMS/Food regional diets (regional per capita consumption of raw and semi-processed agricultural commodities). http://apps.fao.org/faostat/ collections?version=ext\&hasbulk=0\&ubset=foodquality.FAO/WHO. 2014

Hem L, Park J, Shim J. Residual Analysis of Insecticides (Lambda- cyhalothrin, Lufenuron, Thiamethoxam and Clothianidin) in Pomegranate Using GC- $\mu$-ECD or HPLC-UVD. Korean J Environ Agric. 2010;29(3):257-65.

Isenring R, Madeley J. Paraquat: Unacceptable Health Risks for Users. 3rd ed. London, UK: Pesticide Action Network UK; 2006

Jayakrishnan S, Dikshit A, Singh J, Pachauri D. Dissipation of Lambda-Cyhalothrin on Tomato (Lycopersicon esculentum Mill.) and Removal of Its Residues by Different Washing Processes and Steaming. Bull Environ Contam Toxicol. 2005:75:324-8.

Khay S, Choi J, Abd E-AM. Dissipation behavior of lufenuron, benzoyphenylurea insecticide, in/on Chines cabbage applied by foliar spraying under greenhouse condition. Bull Environ Contam Toxicol. 2008;81:369-72.

Lu M-X, Jiang WW, Wang J-L, Jian Q, Shen Y, et al. Persistence and Dissipation of Chlorpyrifos in Brassica Chinensis, Lettuce, Celery, Asparagus Lettuce,
Eggplant, and Pepper in a Greenhouse. PLoS ONE. 2014;9(6):e100556. doi:10.1371/journal.pone.0100556.

Malhat F, Hassan A. Level and Fate of Etoxazole in Green Bean (Phaseolus vulgaris). Bull Environ Contam Toxicol. 2011:87(2):190-3.

Malhat F, Fayz AE-S, Loutfy NM, Ahmed MT. Residues and dissipation of the pesticide emamectin benzoate under Egyptian field conditions: A case study. Toxicol Environ Chem. 2013;95(7):1099-107.

Malhat F, El Sharkawi H, Loutfy N. and Ahmed M. Field dissipation and Health hazard Assessment of Fenhexamid on Egyptian Grapes. Toxicological \& Environmental Chemistry. 2014-a; 96 (5), 722-729.

Malhat, F., Loutfy, N. and Ahmed, M. (2014-b). Dissipation Kinetics of Novaluron in Tomato: An Arid Ecosystem Pilot Study. Toxicological \& Environmental Chemistry, 96(1), 41-47.

Malhat F, Watanabe H, Youssef A. Degradation profile and safety evaluation of methomyl residues in tomato and soil. Hell Plant Prot J. 2015:8(2):55-62.

Mathirajan VG, Natarajan K, Kuttalam S, Chandrasekaran S, Regupathy A. Efficacy of lambda-cyhalothrin (Karate $5 \mathrm{EC}$ ) against brinjal shoot and fruits borer (Leucinodes orbonalis Guen.). Pestic Res J. 2000;12:117-9.

Roberts JMF, Hodgson CJ, Jackai LEN, Thottappilly G, Singh S. Interaction between two synthetic pyrethroids and the spread of two non-persistent viruses in cowpea. Ann Appl Biol. 1993;122:57-67.

SANCO/12571/2013. Guidance document on analytical quality control and validation procedures for residues analysis in food and feed. 2013.

Seenivasan S, Muraleedharan NN. Residues of lambda-cyhalothrin in tea. Food Chem Toxicol. 2009;47:502-5.

Tomlin, C. 2006. The e-Pesticide Manual, 13th edition. Edited by The British Crop Protection Council Publication. Farnham, UK.

Vazquez P, Mughari A, Galera M. Application of solid-phase microextraction for determination of pyrethroids in groundwater using liquid chromatography with post-column photochemically induced fluorimetry derivatization and fluorescence detection. J Chromatogr A. 2008;1188(2):61-8.

Voutsas E, Vavva C, Magoulas K, Tassios D. Estimation of the volatilization of organic compounds from soil surfaces. Chemosphere. 2005;58(6):751-8.

WHO. Guidelines for predicting dietary intake of pesticide residues (revised), WHO, Geneva, 1997, WHO/FSF/FOS/97.7. 1997.

Zhang ZY, Liu XJ, Yu XY, Zhang CZ, Hong XY. Dynamics of pesticide residues in the autumn Chinese cabbage (Brassica chinensis L.) grown in open fields. Pest Manag Sci. 2006;62:350-5.

Zhao S. Plant chemical protection. 3rd ed. Beijing: China Agricultural Press; 2000.

\section{Submit your manuscript to a SpringerOpen ${ }^{\circ}$ journal and benefit from:}

- Convenient online submission

- Rigorous peer review

- Immediate publication on acceptance

- Open access: articles freely available online

- High visibility within the field

- Retaining the copyright to your article

Submit your next manuscript at $>$ springeropen.com 